\title{
Dzieci jako adresaci i odbiorcy reklam telewizyjnych
}

\section{KEY WORDS}

"television childhood", "home" variation of advertisement, victim unaware of the coming danger, the initiator of shopping, „an advertisement for children"

\begin{abstract}
Starosta Anna Maria, Dzieci jako adresaci i odbiorcy reklam telewizyjnych [Children as Recipients of Advertising]. Kultura - Społeczeństwo - Edukacja nr 2, 2012, Poznań 2012, pp. 173-188, Adam Mickiewicz University Press. ISBN 978-83-232-2528-7. ISSN 2300-0422

Living in XXI century, experiencing personally technological and psycho social changes that modern world provides us with, usually we cannot see many phenomena. One of them is undoubtedly the impact of TV commercials on children's personality development process. - Yet, it has become one of the most important factors affecting the child in the process of the social - economic development that exerts great influence on the way of thinking and behavior.

It mainly results from the fact that children today live in a world completely different from previous generations to such an extent that more and more often their childhood is described as "television childhood". The child starts to experience the television (and what comes with it - TV commercials) at home continues throughout the childhood and his youth. A particular concern is the fact that children nowadays have a contact with the medium very early - it starts once their level of development allows them to focus on the screen for some (not long though) time. The range of their contact with the small screen is very wide - what is the most important - it is systematic, daily, lasting for many hours, it has the multifaceted nature and individual character.
\end{abstract}

W XXI wieku, gdy doświadczamy technologicznych, psychospołecznych i kulturowych przemian, jednym $\mathrm{z}$ istotnych zjawisk wartych podjęcia $\mathrm{w}$ humanistycznym dyskursie jest niewątpliwie wpływ telewizji oraz nierozłącznie z nią związanej reklamy telewizyjnej na proces kształtowania osobowości dzieci.

W krajach zachodnich na wyjątkowość dzieci jako adresatów reklam zwrócono uwagę w połowie ubiegłego stulecia, w Polsce zainteresowanie tą problematyką odnotowano w latach dziewięćdziesiątych. Dzieci zaczęto postrzegać nie tylko 
jako konsumentów wielu dóbr oraz aktywnych uczestników rynku, ale także jako instrumenty służące do pozyskania dorosłych konsumentów. Pisząc ściślej, przemysł reklamowy jest zainteresowany dziećmi z trzech zasadniczych powodów: po pierwsze - stanowią rynek pierwotny ( $\mathrm{z}$ ang. primary market), tzn. same dokonują zakupów, po drugie - stanowią rynek wpływowy ( $\mathrm{z}$ ang. influence market), a więc wpływają na innych (przede wszystkim rodziców), by dokonali zakupu, i wreszcie po trzecie - stanowią przyszły rynek ( $\mathrm{z}$ ang. future market), co w praktyce oznacza, że dzieci kiedyś dorosną, a wtedy będą mogły dokonać jeszcze większych zakupów (por. Jasielska, Maksymiuk, 2010: 24). Można zatem mówić o potrójnej funkcji, jaką mają do spełnienia dzieci w „reklamowym teatrze”: $\mathrm{z}$ jednej strony jest to rola decydenta, z drugiej - inicjatora zakupów, z trzeciej - bezpośredniego nabywcy.

O tym, że telewizja bezapelacyjnie zajmuje ważne miejsce w życiu współczesnego dziecka, nie trzeba chyba nikogo przekonywać. Szczególne znaczenie ma to w przypadku dzieci najmłodszych, bowiem jest to faza rozwojowa, w której w niezwykle intensywny sposób, na drodze interakcji, dziecko poznaje środowisko społeczne i wzajemne relacje zachodzące w procesie międzyludzkiej komunikacji. Wynika to przede wszystkim z faktu, iż współczesne dzieci żyją w świecie całkowicie innym niż poprzednie pokolenia, do tego stopnia, że coraz częściej ich dzieciństwo określane bywa mianem „dzieciństwa telewizyjnego”. Odbiór programów telewizyjnych przez dziecko rozpoczyna się $\mathrm{w}$ domu rodzinnym i trwa przez cały okres dzieciństwa oraz młodości. Szczególnym niepokojem napawa fakt, iż obecne dzieci bardzo wcześnie mają kontakt z tym medium - ma to miejsce w zasadzie od momentu, kiedy ich poziom rozwoju umożliwia im skupienie uwagi na ekranie przez pewien (niekoniecznie długi) czas. Z kolei zakres ich kontaktów ze szklanym ekranem jest bardzo szeroki - ma systematyczny, codzienny, wielogodzinny oraz wieloaspektowy charakter1․ Ponadto dzieci coraz częściej oglądają telewizję w sposób „nawykowy”, niejednokrotnie sprawiając wrażenie nieobecnych, silnie zaangażowanych w akcję, przy czym rzadko potrafią odczytać przesłanie, zwłaszcza nieskierowanych do nich audycji. Nie sposób również nie wspomnieć o tym, że dzieci uczą się samej telewizji oraz bycia telewidzem, ramówki programowej, a także telewizyjnych konwencji, ponadto przyzwyczają się do telewizyjnych środków ekspresji.

1 Według moich szacunków dzieci w wieku przedszkolnym oraz młodszym wieku szkolnym poświęcają na oglądanie telewizji od 4 do 5 godzin dziennie, przy czym podczas weekendów czas ten wydłuża się średnio nawet o 3 godziny, co oznacza, że w dni wolne od przedszkola i szkoły dzieci oglądają telewizję nawet przez 8 godzin. Również dalsze analizy mogą przyprawić o zawrót głowy - otóż, przyjmując za punkt wyjścia powyższe dane, łatwo doliczyć się, iż najmłodsi wpatrują się w szklany ekran średnio przez 41 godzin tygodniowo, 174 godziny miesięcznie i 2088 godzin rocznie. Gdyby ponadto doliczyć do tego dodatkowy czas przeznaczony na oglądanie telewizji w związku z koniecznością pozostania dziecka w domu np. spowodowanego chorobą lub świętami, wówczas liczba ta mogłaby wzrosnąć nawet o 100 godzin. 
Treści przekazywane za pośrednictwem telewizji docierają masowo do małych odbiorców, wywierając na nich różnorodny wpływ. Przede wszystkim telewizja fascynuje, dostarcza różnorodnej rozrywki, albowiem kiedy telewizor jest włączony, płyną nieprzerwane obrazy i dzieci są nieustannie „bombardowane” nowymi audiowizualnymi ofertami, dostarczającymi coraz silniejszych wrażeń i nieznanych dotąd pomysłów. Ponadto telewizja jest dla dziecka (zresztą podobnie jak i dla dorosłych) jakże dobrym i wygodnym towarzyszem - nie zadającym pytań i nie oczekującym współdziałania (zob. Samborska, 2004: 52). Zjawisko, w którym to pierwszym interlokutorem małego dziecka staje się właśnie telewizja, nabiera szczególnego znaczenia w obliczu nagminnego przejmowania przez telewizję obowiązków wychowawczych rodziców zajętych zawodowymi i domowymi obowiązkami. W efekcie odbiór programów telewizyjnych przez najmłodszych ma charakter indywidualny (tzn. bez wiedzy i obecności osób dorosłych) i przypadkowy, ponadto zazwyczaj nie poprzedza go żadna selekcja. A to z kolei sprawia, że mali telewidzowie mają do czynienia z prawdziwą mozaiką wpływów oraz krzyżowaniem i przenikaniem się treści.

Nie mniej uprzywilejowane miejsce w życiu dziecka zajmuje reklama telewizyjna. O jej szczególnej roli decyduje w dużej mierze specyfika samego nośnika, który to, odwołując się do najważniejszych receptorów człowieka (wzroku i słu$\mathrm{chu}$ ), pozwala na stworzenie przekazu kierowanego do szerokiego grona adresatów (zob. Ryłko-Kurpiewska, 2008: 15-16). Przy czym w ostatnich latach owo grono odbiorców nader często stanowią właśnie dzieci, do których adresuje się coraz więcej przekazów reklamowych. Ponadto o wyjątkowo silnym oddziaływaniu telewizyjnego przekazu reklamowego na dzieci świadczy fakt, iż żadna inna forma reklamy nie dociera tak intensywnie do dziecka. Dzieje się tak za sprawą bogatych środków technicznych, które pozwalają na sterowanie wyobraźnią dziecka. Umożliwia to zestawianie za sobą różnych elementów treściowych, wykorzystywanie fabuły, symboli, muzyki, perswazji słownej, a przede wszystkim bazowanie na emocjach młodego widza (zob. Smółka, cyt. za: Lizak, 2006: 103).

Najmłodsi niezaprzeczalnie uwielbiają, a wręcz „kochają”, oglądać reklamy telewizyjne, które cieszą się ogromną i niesłabnącą popularnością. Ponadto dzieci są bardzo wytrwałymi i wiernymi odbiorcami komunikatów reklamowych - oglądają je chętnie niezależnie od tematu, nie przywiązując większej wagi do rzeczywistego intencjonalnego adresu². Współcześnie dzieci są nieustannie otoczone, a wręcz „osa-

2 Zebrane w lipcu 2012 r. dane dotyczące czasu spędzanego przez dzieci przed ekranem telewizora umożliwiły mi oszacowanie czasu poświęcanego na oglądanie reklam telewizyjnych. Otóż według moich szacunków dzieci spędzają około godzinę dziennie na oglądanie telewizyjnych spotów reklamowych, a w przypadku weekendów od 1,5 do nawet 2 godzin - co stanowi 1/3 całego czasu poświęcanego $\mathrm{w}$ ciągu dnia na kontakt $\mathrm{z}$ tym medium. W praktyce oznacza to, że najmłodsi oglądają w ciągu zaledwie jednego dnia nawet do 133 reklam (doliczając do tego wcześniej wspo- 
czone" przez reklamę telewizyjną, stanowiącą w zasadzie element ich naturalnego środowiska. Wynika to z faktu, iż reklamy zajmują znaczny procent czasu programów telewizyjnych, przez co niemożliwe staje się ich nieoglądanie. Programy telewizyjne w prasie są publikowane w taki sposób, jakby poszczególne audycje następowały bezpośrednio po sobie, np. 18:25 Klan; 19:00 Wieczorynka; 19:30 Wiadomości, sport itd., w rzeczywistości jednak między zakończeniem jednego a rozpoczęciem drugiego jest tzw. czas pusty (zob. Braun-Gałkowska, 2008: 63-64). Jest to czas, umieszczany między programami, a pominięty $\mathrm{w}$ prasowych programach telewizyjnych, przeznaczony na reklamy i zwiastuny. Pisząc ściślej, reklamy telewizyjne stały się nierozerwalną częścią programów, poprzedzają je, kończą lub są emitowane $\mathrm{w}$ ich trakcie, przy czym, wielokrotnie powtarzane, utrwalają się $\mathrm{w}$ pamięci dziecka, wywołując określone skojarzenia z konkretnymi produktami. W przypadku prywatnych stacji telewizyjnych czas pusty przeznaczony właśnie na filmy reklamowe znajduje się również w trakcie dłuższych programów, w telewizji publicznej proceder ten nie ma miejsca - niemniej jestem przekonana, iż jest to wyłącznie kwestią czasu³.

Warto również zwrócić uwagę na zjawisko, które fachowo nazywa się „ubezwłasnowolnieniem" przez reklamę (zob. Kossowski, 1999: 183). Jego efektem jest nawykowe oglądanie bloków reklamowych, ale i nawykowe (długotrwałe, pozbawione selekcji) korzystanie z telewizji w ogóle. To z kolei może stanowić podstawę do zaistnienia perswazyjnego wpływu reklamy na dziecko, jeśli chodzi o zachowania konsumenckie. W praktyce oznacza to, że dziecko, pomimo deklarowanej niechęci do reklam, przy jednoczesnej bardzo dobrej ich znajomości może, po pierwsze, dokonywać zakupu reklamowanego towaru, a po drugie, wpływać na decyzje dorosłych. Nie sposób również nie wspomnieć, iż coraz częściej obserwuje się, jak najmłodsi przerywają dla komunikatów reklamowych swoje ulubione zabawy, meldując się na baczność przed „generałem reklamą”.

minany czas wolny, liczba ta może się zbliżać nawet do 180). Choć wydaje się to niewiarygodne, oznacza to, że dzieci oglądają około 1025 reklam tygodniowo i 4366 miesięcznie, z kolei w skali roku mają kontakt z prawie 53000 reklam (w przybliżeniu jest to niemal 400 godzin spędzonych na oglądaniu telewizji).

3 Z przeprowadzonych przeze mnie badań wynika, że podczas oglądania jednego programu w czasie najwyższej oglądalności (piątek, od godz. 20:00 do godz. 23:00) stacje telewizyjne nadawały ogromną ilość reklam i zwiastunów. I tak, oglądając film w TVP1 włącznie przed i po jego zakończeniu doliczyłam się 21 reklam i 6 zwiastunów, podobnie rzecz się miała w przypadku TVP2 - 24 reklamy i 6 zwiastunów. Natomiast w przypadku stacji komercyjnych TVN i Polsat liczba reklam przyprawiała o zawrót głowy. W trakcie jednej reklamy w Polsacie obejrzałam średnio 37 reklam i 5 zwiastunów. Zważywszy, że bloków reklamowych było 4, plus blok przed i po zakończeniu filmu, możliwe jest, że włącznie obejrzałam około 222 reklamy (!) i 30 zwiastunów. W przypadku TVN podczas jednej przerwy reklamowej za każdym razem emitowano 33 reklamy oraz 4 zwiastuny. W trakcie filmu miały miejsce 3 przerwy, plus blok reklamowy przed i po filmie, w efekcie czego prawdopodobnie obejrzałam 165 reklam i 20 zwiastunów. Dane empiryczne pochodzą z lipca 2012 r. 
Ta „domowa” odmiana reklamy stała się czynnikiem kształtującym wewnętrzny świat dziecięcych wyobrażeń, przeżyć oraz wartości. Przyczyn owego stanu należy upatrywać w tym, iż ta szeroko rozumiana forma społecznego komunikowania się, będąca syntezą wątków i zjawisk kultury masowej XXI wieku, znalazła prostą i jakże skuteczną drogę do dziecka (por. Kossowski, 1999: 268). Pisząc o prostej drodze, mam tu na myśli fakt, iż reklama bez jakichkolwiek skrupułów wykorzystuje obniżony w stosunku do nich krytycyzm dzieci, brak zrozumienia ich intencji oraz brak możliwości obrony przez zawartą w nich perswazją. To z kolei stwarza nieograniczone pole do działania dla reklamodawców, którzy, wykorzystując typowy dla najmłodszych odbiór reklam, kształtują je w sposób, który intencjonalnie zakłada poboczne odczytanie komunikatu.

Dzieci są również otaczane czujną uwagą reklamodawców z uwagi na fakt, iż to one - w przeciwieństwie do odbiorców dorosłych - najchętniej oglądają rekla$\mathrm{my}^{4} \mathrm{i}$ wierzą $\mathrm{w}$ przedstawione w nich informacje. Są więc zarówno dla nadawców, producentów, jak i twórców reklam idealnymi adresatami - przede wszystkim dlatego, że czerpiąc przyjemność płynącą z odbioru reklam, nie zauważają perswazji i namawiają rodziców do zakupu. W efekcie czego reklamodawcy wykorzystują środki manipulacji wobec bezbronnych i naiwnych jeszcze dzieci, w myśl zasady „wszystkie chwyty dozwolone”. Jest to tym bardziej niebezpieczne, że najmłodsze dzieci zgodnie z rytmem ich rozwoju nie mają jeszcze wykształconych wszystkich komunikacyjnych umiejętności, a co za tym idzie - odpowiedniej selekcji odbieranych bodźców (zob. Walat, 2007: 169). Owocuje to tym, że dzieci stały się bardzo łatwą zdobyczą w potężnym, manipulowanym przez dorosłych świecie konsumpcji. Dzieje się tak ponieważ mają one pewną cechę, określaną jako „syndrom łatwego łupu". Ów łatwy łup ( $\mathrm{z}$ ang. sitting duck - siedząca kaczka) to w myśliwskich realiach ofiara, która siedzi sobie spokojnie i wystawia się na cel myśliwego, nieświadoma nadchodzącego niebezpieczeństwa. Dzieci są dokładnie takim samym łatwym łupem, albowiem są bezbronne wobec wpływu reklam, ponieważ ich umiejętności rozwojowe - między innymi umiejętność logicznego myślenia i co szczególnie istotne zdolność odróżniania rzeczywistości od fantazji oraz prawdy od fikcji - dopiero się kształtują (zob. Acuff, Reiher, 2006: 14, 24)

Wszystko to sprawia, że zdefiniowanie pojęcia "reklama dla dzieci” nie jest wcale takie proste, jak mogłoby się wydawać. Wynika to $\mathrm{z}$ faktu, iż jest to termin bardzo niejednoznaczny - niezwykle pojemny, o jakże szerokim zakresie odniesienia (zob. Lizak, 2006: 85). Obejmuje bowiem zarówno komunikaty reklamowe adresowane bezpośrednio do dzieci (np. reklamy zabawek i słodyczy), jak i spoty reklamowe adresowane jednocześnie do dzieci i dorosłych (np. reklamy produk-

${ }^{4}$ Dzieci w wieku przedszkolnym oraz wczesnym wieku szkolnym w zasadzie od momentu istnienia rynku reklamowego w Polsce stanowią grono najwierniejszych widzów przez co i jedną z najliczniejszych grupę adresatów reklamy (por. Kossowski, 1999: 92). 
tów mlecznych); ale i również reklamy promujące towary dla dzieci, choć skierowane do ich rodziców, (np. reklamy kosmetyków, środków czystości czy leków przeznaczonych dla dzieci). Zawiera również trzeci typ reklam, mianowicie: komunikaty reklamowe kierowane do dorosłych za pośrednictwem dzieci - są to reklamy produktów przeznaczonych dla szerokiego kręgu odbiorców (np. reklamy proszków do prania lub płynów do zmiękczania), wykorzystujące wizerunek dziecka w przekazie perswazyjnym (por. Lizak, 2006; Ryłko-Kurpiewska, 2008). W praktyce oznacza to, że nawet te reklamy, których docelowymi odbiorcami są dorośli, wpisują się tak naprawdę w reklamę dziecięcą.

W przekonaniu A. Ryłko-Kurpiewskiej (2008: 37) wyobrażenie potencjalnego adresata reklamy odgrywa kluczową rolę w tworzeniu aktu komunikacji. Szczególnie istotne jest wprowadzenie do reklamy takiego typu bohatera, który będzie oddziaływał na odbiorcę poprzez swój wizerunek, powodując tym samym, że zaangażuje się on w odbiór komunikatu. W związku z tym do reklamy wprowadza się postać wyobrażonego adresata, do którego odbiorca chciałby się upodobnić (bohatera, który poprzez swoją charakterystykę ma spowodować chęć identyfikacji ze strony odbiorcy), bądź postać mającą wywołać pozytywne nastawienie względem komunikatu. Warto podkreślić, że w reklamach dla dzieci są to zazwyczaj postacie animowane oraz bohaterowie znani z filmów rysunkowych, a także zwierzęta. Nie sposób również nie wspomnieć o postaci dziecka - w końcu to ono, korzystające $\mathrm{w}$ spocie reklamowym $\mathrm{z}$ różnego rodzaju towarów i usług, jest często większym bodźcem niż rzeczywiste walory danego towaru. Co szczególnie istotne, w telewizyjnych komunikatach reklamowych najczęściej pojawia się bohater - dziecko, który odpowiada zewnętrznym cechom domniemanego adresata, mam tu na myśli wiek, płeć, zainteresowania, miejsce zamieszkania, grupę środowiskową, a także rodzaje odczuwanych potrzeb i skłonności do wybierania pewnych zabaw czy przeżycia konkretnych doświadczeń. Zasadniczym celem wyboru konkretnego bohatera jest decydowanie o pozyskaniu zaplanowanego dla komunikatu grona adresatów, a w konsekwencji rzeczywistych odbiorców reklamy. Przy czym sytuacja ta dotyczy zarówno typowania wyobrażonych wizerunków adresatów bezpośrednich, jak i pośrednich, dla których to zostały zaplanowane w reklamie konkretne role. W przypadku spotów reklamowych kierowanych wyłącznie do dzieci mamy do czynienia z dzieckiem jako bezpośrednim adresatem reklamy oraz konsumentem reklamowanego produktu. Natomiast w reklamach kierowanych do osób dorosłych dziecko jest pośrednim adresatem reklamy.

Rzecz jest o wiele bardziej skomplikowana w przypadku komunikatów reklamowych kierowanych równocześnie do dzieci i osób dorosłych, albowiem mamy do czynienia z trzema odmiennymi wizerunkami adresatów. Po pierwsze - dziecko jest bezpośrednim adresatem reklamy, ale i znakiem komunikatu, tzn. wizerunek dziecka ma osłabić krytycyzm dorosłego adresata i wywołać u niego jak najbar- 
dziej pozytywne emocje. Świetnym przykładem mogą być tu reklamy rozmaitych środków czystości, w tym proszków do prania. W komunikatach reklamowych tego typu na temat walorów produktu bardzo często wypowiadają się dzieci, które są wyobrażonymi winowajcami uporczywych zabrudzeń powstałych na ubraniach. Drugim wyobrażonym adresatem zazwyczaj są matki, które na ogół niewiele mówią i nie oceniają zachowania dzieci brudzących ubrania. Na podstawie sekwencji obrazów przedstawiających postępowanie matek odbiorca ma odnieść wrażenie, że doskonale radzi sobie ona z plamami. Jak się okazuje, zabrudzone ubrania dzięki proszkowi nie tylko są czyste, ale także po wyciągnięciu z pralki wyglądają na wyprasowane i zupełnie nowe (brakuje im tylko metek). Dziecko jako odbiorca tych reklam ma odnieść wrażenie, iż namawiając mamę na zakup reklamowanego proszku, wyświadcza jej przysługę, z kolei sobie ułatwia życie, bowiem przedstawiany produkt nie tylko ułatwia pranie, ale i przyczynia się do tego, że mama nie będzie narzekać na wyrządzone przez dziecko szkody. W przypadku drugim dziecko jawi się nam jako ogniwo pośrednie w dotarciu do dorosłego klienta (ma swoją namową skłonić do zakupu osoby dorosłe). Warto również dodać, iż zdarza się, że adresatem pośrednim czyni się dziecko, które ma skłonić rodziców, aby dokonali oni zakupu na rzecz kogoś trzeciego - przeważnie babci lub dziadka. Przykład mogą stanowić emitowane (ze zwiększoną częstotliwością) przed Dniem Babci i Dniem Dziadka rozmaite reklamy preparatów witaminowych lub wzmacniających. Przy czym w komunikatach tych najczęściej wskazuje się na rodzaj korzyści satysfakcjonujący zarówno dla dziecka (na przykład zakup preparatu wzmacniającego dla dziadka może spowodować, że będzie miał on więcej siły, by bawić się ze swoimi wnuczętami), dla jego rodziców (czerpiących radość z bycia darczyńcami), jak i samego użytkownika produktu (przedstawiana w reklamie babcia jest zadowolona $\mathrm{z}$ właściwości produktu, dzięki czemu czuje się młoda i pełna wigoru). I wreszcie sytuacja trzecia, w której mamy do czynienia z dzieckiem jako adresatem zarówno bezpośrednim, jak i pośrednim. Jest to sytuacja, z którą można się spotkać przy emisji dwóch wariantów jednego produktu, kierowanych osobno do dzieci i osobno do dorosłych, w których możliwe jest nakładanie się ról poszczególnych adresatów (por. Ryłko-Kurpiewska, 2008: 37-38 i nast.).

Twórcy reklam stosują różnego rodzaju działania, by trafić bezpośrednio do dzieci, a także, by wykorzystując ich wizerunek, wpłynąć na dorosłych. W efekcie czego dziecko występuje w reklamie w podwójnej roli: jako potencjalny klient oraz jako aktor pozyskujący dorosłego klienta. Generalnie rzecz ujmując, obecność dzieci w reklamach produktów dla nich przeznaczonych jest uzasadniona, albowiem dziecko jako bohater reklam bardziej przyciąga rówieśników, jest szybciej akceptowalny, ale, i co szczególnie istotne, zapewnia im wiarygodność przekazu. Dziecko występuje wówczas w roli „paraautorytetu”; dzieje się tak, ponieważ dziecko nie ma predyspozycji, aby być autorytetem, niemniej może inspirować innych 
do podejmowania podobnych zachowań (bohater reklamy inicjuje pewną modę, np. na posiadanie określonej zabawki). Obserwator (widz) ze względu na podobieństwo do aktora może się z nim utożsamić i uruchomić proces naśladownictwa, czyli powtórzenia zachowania obserwowanego u modela. Jest to powszechnie znany w psychologii (wyjątkowo popularny wśród dzieci i młodzieży) mechanizm uczenia się zachowań społecznych na drodze obserwacji (zob. Jasielska, Maksymiuk, 2010: 84). Warto również wspomnieć, że występujące w reklamach dzieci swoim zachowaniem często wskazują na chęć nawiązania kontaktu z odbiorcami. Czynią to zazwyczaj poprzez podkreślanie zwrotów typu: „baw się z nami”, „graj z nami”, „przyłącz się do nas” itp. Zabiegi tego typu wynikają zapewne z badań nad tak zwaną percepcją społeczną, które dowodzą, że na tym poziomie komunikacji odbiorcy dostrzegają wyrazy akceptacji, a także życzliwości ze strony innych osób i tym samym się odwzajemniają. Szczególnie wyraziste są w tym względzie reklamy zabawek, a zwłaszcza lalek. Dzieje się tak, ponieważ komunikaty tego typu mają dostarczać dzieciom swoistych inspiracji do zabaw, których istotą jest odgrywanie rozmaitych ról pełnionych przez dziewczynki osobiście lub za pośrednictwem lalek. Przy czym w zabawach tych dzieci najczęściej naśladują zachowania i czynności dorosłych (por. Ryłko-Kurpiewska, 2008: 39-41).

Również sama postać dziecka, ale także jego głos i sposób zachowania (bardzo często będącego wyreżyserowaną spontanicznością) wpływają na skuteczność reklamy. W zasadzie już samo pojawienie się dziecka w reklamie powoduje pozytywne nastawienie widza. Wizerunek dziecka w reklamach dla dorosłych można wykorzystywać na dwa sposoby. W pierwszym przypadku dziecko pojawia się $\mathrm{w}$ reklamie produktu dla dzieci. Jest to o tyle istotne, że rodzice zwracają uwagę $\mathrm{w}$ przekazie przede wszystkim na elementy emocjonalne, związane $\mathrm{z}$ ich stosunkiem do dziecka (np. jego dobrem, bezpieczeństwem, itd.), a nie na argumenty o charakterze racjonalnym. Natomiast $\mathrm{w}$ drugim przypadku dziecko pojawia się w reklamie produktów przeznaczonych dla dorosłych, co z kolei wzbudza poczucie zaufania. Zjawisko to jest szczególnie wyraźne, gdy w reklamie występują małe dzieci - charakterystyczny dla nich wygląd oraz nieporadne ruchy wyzwalają w osobach dorosłych zachowania opiekuńcze, rozczulenie i tkliwość (por. Doliński, 2003: 152-156). Pozytywne emocje wywołane widokiem „słodkiego bobaska" są kojarzone z reklamowanym przez niego produktem. Ponadto u jego źródła leżą wspomnienia z dzieciństwa bądź też skojarzenia $\mathrm{z}$ własnymi dziećmi, które wywołują radość, wzruszenie i rozczulenie, a w konsekwencji powodują niepowtarzalny klimat przekazu. W obydwóch przypadkach pojawiania się wizerunku dziecka w reklamie skierowanej do dorosłych może także chodzić o „projektowanie” sytuacji, w których dziecko jest przez rodziców dopuszczane do podejmowania wspólnych decyzji konsumenckich i uczestniczy w dokonywaniu zakupów. 
Pojawianie się dzieci w reklamach towarów przeznaczonych dla dorosłych rodzi obawę o nadużywanie dzieci do celów komercyjnych. Generalnie dyskusyjny staje się charakter etyczny takich reklam. Podkreśla się bowiem, że dziecko funkcjonuje w nich w sposób przedmiotowy, jest wmanipulowane w mechanizm perswazji, która (kosztem dziecka) ma przyciągać dorosłego konsumenta. Trudno jest jednak wyznaczyć granicę między reklamą, w której dziecko jest aktorem promującym towary dla dzieci, a reklamą wykorzystującą postać dziecka jako sposób wpływania na uczucia dorosłych, a w konsekwencji na ich konsumpcyjne zachowania. Ich działanie jest bardzo proste: otóż widok zadowolonych rówieśników własnego dziecka, mieszkańców bezproblemowego świata (w końcu świecie reklamy dziecko jawi się nam jako istota całkowicie bezbronna i niewinna, której naturalnym przeznaczeniem nie jest nic innego jak szczęście i radość) - którym wcześniej już udało się zachęcić nasze dziecko do agitacji na rzecz tej lub innej marki - przekonuje rodziców o słuszności ulegania namowom dziecka. Tym bardziej, że po konsumpcji reklamowanego produktu dziecko stanie się tak samo radosne, lubiane, energiczne, błyskotliwe i co najważniejsze - będzie kochało swoich rodziców dokładnie tak, jak uwidoczniono na ekranie telewizora. Generalnie rzecz ujmując, reklamy kierowane do rodziców sugerują im określone działania, opierając się na swoistej strategii, którą da się ująć w postaci następujących schematów: każda matka, która bezgranicznie kocha swoje dziecko, powinna kupować produkt „X”, ponieważ produkt „X” jest całkowicie bezpieczny, gdyż został przebadany przez dermatologów i cieszy się dobrą opinią lekarzy specjalistów, nie zawiera parabenów i sztucznych barwników, w efekcie czego nie podrażnia skóry, stworzono go z myślą o wyjątkowych potrzebach Twojego dziecka i Twojemu dziecku przyniesie on nieustającą radość i szczęście. W ten schemat (mniej lub bardziej modyfikowany) wpisana jest treść reklamy. Niedostosowanie się rodzica do płynących z niej zaleceń powinno wywołać poczucie winy. Jednakże pozbyć się go jest bardzo łatwo - wystarczy sięgnąć po oferowany w reklamie produkt, by poczuć, że nasze dziecko otrzymuje od nas to, co najlepsze. W emocjonalnym obrazie i kilku kluczowych słowach mieści się wystarczająca dawka sugestii, by zjednać odbiorcę, zmodyfikować jego zachowania, a w efekcie pozyskać w nim klienta. Tak więc podatność rodziców na argumenty w postaci dziecka i uczuć z nim związanych jest ogromna, a skuteczność przekazu z obecnością (chociażby w tle) dziecka bardzo wysoka.

Coraz częściej na rynku dziecięcym można zauważyć pewien sposób łączenia reklamy dla dziecka z reklamą dla rodzica. A. Ryłko-Kurpiewska (2008: 17-18) wskazuje, iż na zmianę tej sytuacji wpłynęły przede wszystkim rezultaty sondaży efektywności reklam, które to wykazały, że dzieci w tym przedziale wiekowym bardzo często współdecydują, a nawet podejmują samodzielne decyzje dotyczące zakupów dokonywanych dla domu i rodziny. Należy również przyznać, że podwójne zaadresowanie komunikatów, w których dziecięcy i dorosły adresat traktowani są 
$\mathrm{z}$ równą uwagą, sprzyja pozyskaniu szerszego audytorium dla reklamy. Przy czym pula możliwych kombinacji w tym obszarze nie została jeszcze wyczerpana, ponieważ istnieją produkty dla dzieci, które reklamowane są przez dorosłych, oraz produkty dla dorosłych reklamowane przez dzieci. Tak więc sytuacja ta stwarza możliwość podwójnego przypisania roli adresata dziecku, mogącemu spełniać funkcję zarówno adresata bezpośredniego (ma to miejsce wówczas gdy to ono ma zdecydować o zakupie i być planowanym konsumentem produktu), jak i adresata pośredniego (gdy ma ono nakłonić do zakupu inną osobę). W praktyce oznacza to, że producent może odnieść podwójny skutek: reklama może zainteresować dziecko i przekazać racjonalne argumenty rodzicom. Nie bez znaczenia jest także fakt, że już samo przedstawienie $\mathrm{w}$ reklamach pozytywnego wizerunku dzieci sprzyja przyjaznemu odbiorowi komunikatu zarówno przez rówieśników reklamowanego bohatera, jak i osoby dorosłe, które widząc dzieci występujące w spocie telewizyjnym, mają, niestety, skłonność do mało analitycznego odbioru treści aktu reklamowego. W każdym bądź razie równoczesne zaadresowanie reklamy do dzieci oraz ich rodziców pozwala z pewnością producentom na uniknięcie kosztów, które musieliby ponieść w przypadku pozyskania tego samego audytorium w inny sposób. Jednakże atrakcyjność owego przedsięwzięcia wydaje się dyskusyjna wobec powstających obecnie różnych wariantów komunikatów reklamowych jednego produktu, przygotowywanych osobno z myślą o dorosłym i dziecięcym adresacie. Sposób przygotowania tych komunikatów z pewnością wiąże się z wiarą w większą skuteczność perswazyjną wypowiedzi skierowanej do jednorodnego grona adresatów. Natomiast $\mathrm{z}$ drugiej strony konieczność dostosowywania komunikatów do grona zróżnicowanego pod względem wieku pozwala na stworzenie oryginalnych wypowiedzi, dzięki czemu zyskują one miano innowacyjnych i nie giną w potoku wielu komunikatów emitowanych w ich sąsiedztwie (zob. Ryłko-Kurpiewska, 2008: 46-47).

Kolejną kwestię stanowi dziecko jako adresat pośredni. Zdarza się bowiem, że dziecko nie jest tylko bezpośrednim odbiorcą przekazów reklamowych, ale także ich mimowolnym adresatem, przy czym mimowolność jest tu określeniem umownym. Nie oznacza bowiem braku intencjonalności ze strony nadawcy, który to konstruuje komunikaty reklamowe w taki sposób, by były one atrakcyjne oraz zrozumiałe dla dzieci, stosując jednocześnie odpowiednie techniki perswazji; liczy również na odbiór dziecięcego widza. Efektem tego są krótkie, mające żywe kolory filmy, wzbogacone o proste i łatwo wpadające w ucho teksty oraz piosenki, zwykle pogodny nastrój, a także animowanych, zwierzęcych i dziecięcych bohaterów. Wszystko to sprawia, że reklama, choć z pozoru kierowana do widza dorosłego, jest w zamierzeniu reklamodawców adresowana również do dzieci - które stanowią ważną i wpływową siłę opiniotwórczą (coraz częściej bywa tak, że to dziecięcy głos jest przy zakupie określonego towaru decydujący) i której producenci nie mogą 
zlekceważyć w strategii działań reklamowych. Wynika to z faktu, iż dzieci szybko zapamiętują i wielokrotnie powtarzają (często przypadkowe) reklamy. Wpływają tym samym na postawę rodziców, tworząc w domu przyjazny klimat dla obojętnych w pierwszych latach życia przedmiotów, takich jak np. środki czyszczące, kosmetyki itp. Według B. Kwarciaka (1999: 283) jest to tak zwany efekt „echa”, który obecnie coraz częściej jest wykorzystywany przez specjalistów zajmujących się reklamą.

Nadawcami adresowanych do dziecięcego odbiorcy spotów reklamowych kierują dwie podstawowe motywacje: po pierwsze - skłonić dziecko do zakupu określonego towaru lub usługi;, po drugie - posłużyć się dzieckiem instrumentalnie, wykorzystać je pośrednio jako „siłę nacisku” na dorosłego konsumenta, w myśl zasad techniki perswazyjnej oddziaływanie pośrednie (por. Kossowki, 1999: 206; Ryłko-Kurpiewska, 2008: 47). Zjawisko to nabiera szczególnego znaczenia w obliczu faktu, iż dzisiejsze dzieci pod wpływem obejrzanych reklam chcą zaspokoić swoje pragnienia, w efekcie czego namawiają rodziców do kupna tego, co zobaczą na ekranie telewizora. Reklama telewizyjna pobudza więc nieistniejące wcześniej (lub nie tak silne) potrzeby i pragnienia, rozbudza ponadto dziecięcą chęć posiadania i orientuje uwagę na dobra materialne. Co szczególnie interesujące, współczesne dzieci obecne przy zakupach wyrażają swe opinie w sposób całkowicie nieskrępowany: doradzają, sugerują, naciskają oraz kontrolują. Ponadto jako konsumentów charakteryzują je takie cechy, jak odwaga w podejmowaniu decyzji, otwartość na nowe produkty, a także podatność na szybkie zmiany związane z postępem cywilizacyjnym.

Jakby tego było mało, reklamodawcy już dawno odkryli, że dzieci nie będą małe przez całe życie i kiedyś dorosną. Jest to o tyle istotne, że wówczas o tę samą grupę osób nie będą musieli konkurować z innymi. Pisząc jaśniej - skuszenie do „dorosłej" reklamy dziecięcego widza, nie czekając, aż dorośnie, daje na przyszłość lojalnego klienta. Reklamodawcy liczą bowiem na to, że odbiorca pozyskany dla danej marki już we wczesnym wieku będzie wierny swoim dziecięcym przyzwyczajeniom w późniejszym okresie swojego życia. Obrazowo nazywa się to „marketingowym walcowaniem narybku" (Szlendak, 2005: 38; zob. też. Andrzejewska, 2007: 55-56; Kwarciak, 1999: 283; Ryłko-Kurpiewska, 2008: 24). Dla przykładu można tu podać, że najnowsze badania marketingowe ujawniają, iż uznanie oraz aprobata, jakie żywią odbiorcy reklam do marki z dzieciństwa, są szczególnie istotne w przypadku samochodów (zob. Ryłko-Kurpiewska, 2008: 24). Zdaniem specjalistów od reklamy przywiązanie dziecka do marki jest proste i przebiega podobnie jak u osób dorosłych. Wiadomo jest, że już przed 7 rokiem życia dzieci świetnie zapamiętują markę, jingle reklamowe, slogany i logo, mimo iż często są one dla nich tworami abstrakcyjnymi niekojarzonymi z określonymi wartościami czy stylem życia. Mechanizm jest następujący: dziecku podoba się zabawka okre- 
ślonej marki i przywiązuje się ono do logo tej marki. Następnie (nawet jeśli nie potrafi jeszcze czytać) wychwytuje znaki graficzne (tzw. logotypy) lub nawet formę graficzną zapisu słownego danej marki, dzięki czemu rozpoznaje markę w każdym możliwym miejscu (podaję za: Jasielska, Maksymiuk, 2010: 23). Warto również dodać, że samo wytypowanie dziecka, które ma się stać w przyszłych działaniach wyobrażonym adresatem reklamy, poprzedzane jest badaniem ekonomicznej atrakcyjności adresata. W praktyce oznacza to, że wprowadza się tzw. wskaźnik „wartości klienta”, który opiera się najczęściej na danych umożliwiających określenie momentu przeprowadzania zakupów, ich częstotliwość oraz materialną wartość. Dopiero dalsze badania umożliwiają określenie życzeniowego adresata reklamy (zob. Ryłko-Kurpiewska, 2008: 24). Najgorsze jednak w pozyskiwaniu dziecka zarówno jako obecnego, jak i jako perspektywicznego klienta jest to, że o ile dorośli ludzie wiedzą o perswazyjnym charakterze reklamy telewizyjnej i z reguły mają krytyczny stosunek do handlowych zapewnień i obietnic (dzięki czemu zdarza się im wymówić posłuszeństwo reklamie i zachować autonomię własnych wyborów), o tyle dziecko nie ma takiej zdolności - jest łatwowierne, bezkrytyczne, nie wie, że reklamy w nienaturalny sposób podsycają potrzeby, w konsekwencji czego podąża za reklamą bezwolnie i lunatycznie, niczym za dźwiękiem czarodziejskiego fletu Szczurołapa. Dzieje się tak, albowiem mają one dla nich bardzo duże znaczenie poznawcze. Zdaniem E. Kasztelan (1999: 90) „Są elementem myśli, emocji i działań dzieci, zajmują dużo miejsca w rozmowach, jakie prowadzą między sobą. Stwierdza się wręcz, iż w obecnych czasach znajomość reklam jest istotnym elementem świadczącym o pozycji dziecka w grupie rówieśniczej”. Reklama ponadto wytwarza w dzieciach przekonanie o istnieniu „realnego" świata pozbawionego wad, pełnego szczęścia, miłości, radości, życzliwości i zawsze kochających się ludzi.

Niestety, prawda jest taka, że w dzisiejszej rzeczywistości medialnej nie sposób uniknąć kontaktu dziecka z reklamą, tak jak trudno zapobiec wpływom reklam na zachowanie dzieci. Niezaprzeczalnie reklama kreuje specyficzny obraz świata, wpływa na wyobraźnie i myślenie - dzieci zaczynają postrzegać świat zgodnie z intencjami twórców reklam i marzą o tym, co reklamuje się w telewizji. Osacza najmłodszych, zapraszając do świata atrakcyjnych towarów będących w zasięgu ręki, gdzie każdy widz ,jest tego wart”. Jaskrawe kolory, animowane postacie, wideoklipowy obraz czy łatwo wpadające w ucho motywy muzyczne - wszystko to zaprzęgnięto do wielkiej perswazyjnej machiny, która nieustannie przekonuje małego widza, że tylko zakup uczyni go szczęśliwym i wartościowym człowiekiem. Dla dziecka nieuzbrojonego w zmysł krytyczny taki przekaz jest niczym magiczne zaklęcie, spod którego uroku nie sposób się uwolnić. Wszystko to prowadzi do tego, iż dziecięcy świat ulega ograniczeniu i wypaczeniu. Dotyczy to szczególnie dzieci najmłodszych, które mają różne cechy poznawcze i emocjonalne i które chłoną przekazy reklamowe (podobnie zresztą jak wszystkie inne informacje) jak 
przysłowiowa „gąbka”. Jak wskazują D.S. Acuff i R.H. Reiher (2006), te niepokojące tendencje reprezentują realne, stale rosnące niebezpieczeństwo dla zdrowego rozwoju, dorastania, a także szczęścia i sukcesu dzieci na całym świecie.

Nieuczciwość reklamodawców i nadawców ma kilka poziomów, spośród których najszerszym jest kwestia, czy w ogóle idea kierowania intencjonalnie do dzieci filmów reklamowych może być uznana za uczciwą i etyczną. Mamy tu bowiem do czynienia - jak to określił P. Kossowski (1999: 273) - „ze swoistą grą reklama - dziecko, w której już na wstępie szanse nie są równe”. Oznacza to, że dziecko niejako „z definicji” znajduje się w gorszym położeniu ze względu po pierwsze - na niewielki zasób doświadczeń życiowych, po drugie - małe kompetencje komunikacyjne i wreszcie po trzecie - $\mathrm{z}$ uwagi silnie emocjonalny charakter odbioru treści kultury. Nie ma bowiem świadomości, że w reklamie chodzi nie tylko o kilkadziesiąt sekund spędzonych przed ekranem telewizora lub kupno jakiejś rzeczy, ale o efekty perspektywiczne: socjalizowanie, przyzwyczajanie do pewnych powtarzalnych wyborów i zachowań, urabianie konsumenta czy tworzenie nawyków konsumpcyjnych.

Reasumując, można uznać, iż kierowanie do najmłodszych komunikatów reklamowych o znacznej sile oddziaływania jest generalnie naruszeniem podmiotowości dziecka - osoby ludzkiej; wywieraniem symbolicznej przemocy przy założonej przez reklamodawców oraz obiektywnie istniejącej nierówności w relacji dziecko-reklama telewizyjna. Działania profilaktyczne zmierzające do zminimalizowania negatywnych skutków oddziaływania reklam telewizyjnych na dzieci niewątpliwie powinno rozpocząć się od wzbudzenia świadomości w społeczeństwie na temat wagi i skali tego problemu. W przypadku dzieci najmłodszych największą rolę $w$ tym procesie odgrywa środowisko rodzinne, a odpowiedzialność spada na pierwszych i najważniejszych opiekunów dziecka - rodziców. Jak podkreśla J. Olech (2004: 151-152), jeśli rodzice nie podważają wiarygodności reklamy, jeśli nie potrafią (lub nie chcą) „odczarować” jej zaklęć, ta będzie tylko rosła w siłę, rozpychając się $w$ Krainie Dziecięcych Marzeń. Przygotowanie do właściwego odbioru reklam powinno zatem rozpocząć się od najmłodszych lat, zwłaszcza, że wygląda na to, iż świat bez reklam jest - niestety - szlachetna utopia.

\section{Literatura}

Acuff D.S., Reiher R.H. (2006). Kidnaping. Jak marketerzy kontroluja umysł Twojego dziecka, tłum. M. Lipiec-Szaforczyk, J. Sugiero. Gliwice

Andrzejewska A. (2007). Magia szklanego ekranu. Zagrożenia plynące z telewizji. Warszawa

Braun-Gałkowska M. (2008). Dziecko osaczone przez reklamy. [W:] Media elektroniczne w życiu dziecka w kontekście wartości wychowawczych oraz zagrożeń. Red. J. Izdebska Białystok

Doliński D. (2003). Psychologiczne mechanizmy reklamy. Gdańsk 
Jasielska A., Maksymiuk R. (2010). Dorośli reklamują, dzieci kupują. Warszawa

Kasztelan E. (1999). Stan zareklamowania. Reklama wobec dziecka w środkach masowego przekazu. Wrocław

Kossowski P. (1999). Dziecko i reklama telewizyjna. Warszawa

Kwarciak B. (1999). Co trzeba wiedzieć o reklamie. Wyd. 2 rozsz. Kraków

Lizak J. (2006). Język reklam dla dzieci. Rzeszów

Olech J. (2004). Wiedźma reklama. [W:] Nigdy nie jest za wcześnie - rozwój i edukacja małych dzieci. Red. T. Ogrodzińska. Warszawa

Ryłko-Kurpiewska A. (2008). Dzieci jako odbiorcy reklam telewizyjnych. Gdańsk

Samborska I. (2004). Dziecko i telewizja. Reklamy i bajki telewizyjne, a zachowania językowe współczesnego przedszkolaka. Bielsko-Biała

Szlendak T. (2005). Leniwe maskotki, rekiny na smyczy. W co kultura konsumpcyjna przemienia mężczyzn i kobiety. Warszawa

Walat W. (2007). Zjawisko przemocy w mediach na przykładzie reklam i gier komputerowych dla dzieci i młodzieży. [W:] Przemoc: konteksty społeczno-kulturowe. T. 2: Kulturowe i edukacyjne aspekty zjawiska. Red. W. Walc. Rzeszów

\section{Children as Recipients of Advertising}

\section{Summary}

Polish children are very tenacious and faithful recipients of commercials - they watch them regardless of the topic, not paying much attention to the actual intentional address. According to my estimates, children spend about an hour a day on watching TV commercials, and in the case of weekends - from 1.5 to 2 hours - which is one third of the total time spent during the day in contact with the medium. In practice, this means that the youngest watch up to 133 ads a day (while during kindergarten or school day-offs, this number may be even closer to 180). Although it seems incredible, this means that children watch about 1,025 ads per week and 4,366 per month, while the annual contact with the Strona commercials amounts to almost 53 000 ads (approximately 400 hours spent on watching television).

This „home” variation of advertisement has become, according to Polish conditions, the part of kids' natural environment, and what goes with that one of the strongest - if not the strongest - factor influencing children' inner world of ideas, experiences and values. The main causes of this statement is that this widely implied form of social communication, which is a synthesis of themes and phenomena of XXI - century mass culture, has found a simple and very effective way to the Polish child. Writing about a simple way I mean the fact that the advertisement without a twinge of conscience takes the advantage of the lowered level of criticism, lack of understanding of intentions and no opportunities to defend themselves. All of this results in the fact that children nowadays have become a very easy prey to a powerful, manipulated by adults, world of consumption. This happens because they have a feature known as "a sitting duck". A sitting duck, in the world of hunting, describes the victim unaware of the coming danger that sits quietly and exposes itself to a hunter. Children are exactly the same easy prey, because they are vulnerable to the presence of advertising, because their development skills - including the ability of thinking logically, and what is the most important the ability of distinguish reality from fantasy - are still taking shape. 
In the western countries, the uniqueness of children as ads recipients was pointed out in the middle of the last century, while in Poland just in the 90s. Since then, children began to be seen not only as consumers but as the instruments of winning adults. Writing more specifically, the advertising industry is interested in children because of three main reasons. First of all, they are the primary market, they make purchases by themselves. Second of all, they are a market influence, and thus affect others (especially parents). And thirdly, they are the future market, which in practice means that children will grow up, and as the adults they will make even more purchases. Therefore, we can assume that they are of great importance and play a triple role the role of the decision maker, on the other hand - the initiator of shopping and finally - the direct purchaser.

This situation makes the clear-cut definition of the notion „an advertisement for children” virtually impossible. It stems from the fact that this is a highly ambiguous, broad and widely used term. It includes both advertising communications aimed directly at children and advertising communications aimed at adults via children - these are the advertisements using the image of a child in the coaxing message. It includes also the third type of the advertisement, namely: advertising spot aimed at both children and adults. First of all, we can deal here with a situation, in which a child is a direct addressee of an advertisement, but also with a communication sign, i.e. the image of a child is used to diminish the criticism of an adult addressee and invoke the most positive emotions in him. In the second case, a child appears as an indirect link on a way to an adult customer (a child's suggestion is to encourage an adult to make a purchase) And finally, the third situation one may encounter when it comes to the launch of two variants of the same product, aimed separately at children and adults, in which overlapping of the roles of the respective customers is possible. In practice, it all means that even the advertisements, the destined addressees of which are adults, fit into the child's advertisement. And if it is not enough, the advertisers discovered it long time ago that children wouldn't be small for the rest of their lives and finally grow up. It is important because, at the time, they will not have to compete with others over the same group of people. To make it clear, persuading a child viewer to an "adult" advertisement, without waiting until it grows up, makes a loyal consumer in the future. The advertisers look forward that an addressee gained from a very early age for some brand, will be faithful to its child's customs when he gets older. To be more precise, it is called ,a marketing rolling of the new blood".

The worst thing in winning a child both as a present and a perspective customer is that adults, who know the persuasive mechanism of TV commercials, usually are critical for the assurances and promises (they can preserve the autonomy of their own choices), whereas the child, who is credulous, uncritical, does not know that the ads in an unnatural way fuel nonexisting needs and desires, also arouse the desire of possession material goods. Consequently the child follows the world of commercials like a lunatic, lured by the sound of a magic flute. The advertisements have a vast cognitive meaning, they produce the belief in the real world without flaws, full of happiness, love, joy, kindness and always loving people.

Unfortunately, the truth is that in the reality of today's media it is impossible to protect our children from the world of advertisement, as well as it is difficult to prevent their behaviour from being influenced. Undeniably, advertising surrounds the youngest everywhere tempting with attractive goods within reach of a hand, because every single viewer is worth it. Bright colours, animated characters, catchy music - all harnessed to a great persuasive machine that constantly convinces the young audience, that buying is the only thing that make them happy and of great worth. 
Therefore, to minimize the negative effects of advertisement on children, we should start preventive actions. There is no doubt that we should start from raising the public awareness on the importance and scale of the problem. For the youngest children, the most important role in this process is plays the family, especially the most important guardians of the child - parents. If they do not undermine the credibility of advertisement, if they cannot (or do not want to) „disenchants" its spells, it will only grow in strength in the Children's Land of Dreams. Preparation for the proper reception of commercials should start from an early age, especially since it seems that the world without advertisements is - unfortunately - a noble utopia. 